\title{
Bakım Planlamalı Uçuş Atama Modeli ve Bir Uygulama
}

\author{
Flight Planning with Maintenance Consideration and an Application \\ Mehmet Anıl ȘAHIN ${ }^{1}$ iD, Gülfem TUZKAYA ${ }^{1}$ (iD \\ ${ }^{1}$ Marmara Üniversitesi, Mühendislik Fakültesi, Endüstri Mühendisliği Bölümü, 34722, İstanbul/Türkiye
}

$\ddot{O} \mathbf{z}$

Bu çalışmanın amacı, hava yolları endüstrisinin karmaşık problemlerinden biri olan bakım rotalama problemine yeni bir çözüm önerisi getirmektir. Çalışma kapsamında öncelikle, hava yolları endüstrisi operasyonlarının temel uygulama ve problemleri, bu uygulamaların literatürdeki yeri temel düzeyde ele alınmıştır. Hava yolları endüstrisi literatürü "Filo Atama, Uçak Rotalama, Bakım Rotalama ve Mürettabat Çizelgeleme" başlıkları altında incelenmiştir. Önerilen, bakım planlamalı uçuş atama modeli, gerçek uçuş verileri ve tasarlanan uçuş filosu için uygulanmış ve bir uçuş programı oluşturulmuştur. Model iki amaç fonksiyonuna sahiptir. Birinci amaç fonksiyonu, kullanılmayan kalan yasal zamanı minimize etmeye çalışırken, ikinci amaç fonksiyonu kullanılmamış uçak kapasitesini minimize etmeye çalışır. İki amaçlı model öncelikli hedef programlama ile çözülmüştür.

Anahtar Kelimeler: Bakım planlama, Uçuş atama

\begin{abstract}
As the main concentration of this study, maintenance routing is one of the most complicated problems of airline industry. In this study, airline industry operations' main applications and subjects are basically summarized and a literature review is briefly presented. Study is conducted under headings of; "Fleet Assignment, Aircraft Routing, Maintenance Routing and Crew Scheduling". A problem consist of real time flight data and a small size fleet is generated and the proposed model is solved to create a route with maintenance consideration. Model which solves the problem has two objective functions. While first objective function tries to minimize remaining legal flight hours of the aircrafts second objective function tries to maximize the capacity utilization of an aircraft according to the demand for the covered flight. The model is solved by using preemptive goal programming.
\end{abstract}

Keywords: Maintenance Planning, Flight Planning

\section{GíRIŞ}

Ticari havacılık endüstrisi, en güvenli ve en hızlı seyahat yollarından birini sunmaktadır. Çok önemli bir iş alanı olan bu endüstride, yöneylem araştırması tekniklerinden sıklıkla faydalanılmaktadır. Havacılık endüstrisinde rotalama ve çizelgeleme problemlerini dört ana başlık altında inceleyebiliriz: Filo atama, uçak rotalama, bakım rotalama ve mürettebat çizelgeleme. Filo atama probleminde rotaların tamamlanacağı uçaklar belirlenmeye çalışılır. Bu filolar bazen yalnızca bir uçak tipinden, bazen birkaç farklı modelden oluşurlar. Karışı filolarda, tüm ihtiyaçları karşılamak için çeşitli kapasite ve menzile sahip uçaklar bulunmaktadır. Uçak rotalama esas olarak uçuş programındaki belirli sayıda uçuşun her birinin filodaki hangi uçakla yapılacağına karar veren çalışmadır. Bakım rotalama, belirli bir periyot için gerçekleşecek uçuşlara uçak ataması yapılırken, uçakların Avrupa Havacılık Güvenliği Ajansı (EASA-European Aviation Safety Agency) yönergelerine göre bakım ihtiyaçlarının da değerlendirilmesini içerir. Bu bakım ihtiyaçları uçaktan uçağa farklılık gösterebilir. Dolayısıyla uçuş programında uçakların her biri için kalan uçuş süresi hesaplanır ve düzenli bakımlar için uçaklara boşluklar yaratılır. Mürettebat çizelgeleme, uçuşlara pilot ve kabin ekibi atanması ile ilgilenir ve gerekli planları yapar [1-2].

Bir uçuş programını planlarken, en önemli noktalardan biri, uçuş saatlerine uygun olarak uçağın bakımının da planlanmasıdır. Her markanın farklı tipte uçakları farklı zaman ve mesafeler sonrasında planlı bakım gerektirir. Bakım süreleri EASA 
tarafından düzenlenmektedir. Bu bakımlar, orta, uzun vadeli bakımlar ve uçuş öncesi kontrolleri başlıklarında üç bölüme ayrılır. Uzun süreli bakımlar ve uçuş öncesi kontrolleri haftalık uçuş planında listelenmemektedir. Çünkü uzun vade bakımları için uçağın filodan alınması ve hangara çekilmesi gerekecektir. Uçuş kontrolleri ise her uçuştan önce yapılır ve çok az zaman alır. EASA yönetmelikleri ile düzenlenen orta vadeli bakımlar, parça değişiklikleri için uçağın hangara alınmasını gerektirir. Firmalar genellikle, uçuş saatleri ile çakışmaması için, bakımlarını uçuş yapılmayacak gece saatlerinde yapmayı planlar. Yukarıda belirtilen nedenlerden dolayı, uçuş planlarını hazırlarken kalan uçuş sürelerinin dikkate alınması, uçakları aktif tutmak için bir avantaj sağlar [3].

Bakım kısıtlı uçuş planlama probleminde temel amaç, bakım gereksinimlerine uygun olarak her uçak için uçuş rotaları oluşturmaktır. Geleneksel bakım kısıtlı uçuş planlama problemleri modelleri yüksek sayıda uçak ve rota seçeneği için çalışır. Plandaki uçuşların sayısı arttıkça, çözüm ve çözüm zamanı için alternatifler katlanarak artmaktadır. Sorunu hafifletmek için bu tür modeller, sütun oluşturma veya satır oluşturma yaklaşımlarıyla adım adım çözülür. Diğer taraftan, Liang ve Chaovalitwongse [3] günlük bakım kısıtlı uçuş rotası problemi için haftalık rotasyon-tur ağı modeli geliştirmişlerdir. Bu çalışmada, uçuş sayısındaki artış çözümün aralığını doğrusal olarak etkilemektedir [3].

Bakım kısıtlı uçuş planlama, havayolu endüstrisinin planlama ihtiyaçlarından sadece biridir. Bu problem hem yolcu uçuşları hem de kargo uçuşları için çözülmelidir, ancak iki problem çeşitli farklılıklar içerir. Yolcu uçuşlarında gecikmelerde sorunlar oluşabilir ve iptal durumları söz konusu olabilir. Kargo uçuşları için ağırlık ve kütle problem oluşturabilir [1].

Bakım kısıtlı uçuş planlama probleminde iki husus önemlidir. Bunlardan biri, uçuş bağlantılarının ihtiyaç duyulandan daha kısa sürede kurulduğu durumları cezalandırmak, diğeri ise bağlı uçuşların değerini arttırmaktır. "Dönüş süresi”, uçağın "minimum bekleme süresinden" kısaysa, gerekli işlemler için yeterli zaman olmayacaktır ve kısa bağlantı süresi cezası uygulanacaktır. Dönüşs süresi, bir uçağın inmesi ile bir sonraki kalkışı arasındaki süreyi açıklayan bir terimdir. Uçağın minimum bekleme süresi, kabin görevlilerinin uçuşlar arasındaki uçakları değiştirmesi için gereken minimum süreyi açıklayan bir terimdir. Kısa bağlantı, 'Takım kurma problemi' için pratik olmayan veya yüksek maliyetli sonuçlara neden olabileceğinden istenmeyen bir olaydır. Bağlı uçuşların değerini arttıran faktör, iki bağlı uçuş arasında uçakta kalan yolcu miktarıdır.
Uçuş dizilerinin bağlanması ve rotaların belirlenmesi konunun literatürdeki en yaygın rastlanan iki problemidir. Kararlar, istasyonlar arasında bakım hizmetini verebilecek, bakım istasyonlarından birinde sona eren uygulanabilir uçuş sıralarını bulmakla ilgilidir [3].

Havayolu sektöründe en büyük maliyetlerden birini bakım giderleri oluşturur. Bu nedenle, bir uçağın yasal uçuş süresini azami ölçüde kullanarak, planlanan bakım süresini limitler dahilinde geciktirerek maliyetleri düşürmek önemlidir. Ekipmanların en son kullanma sürelerine kadar kullanılmamas1 ekstra maliyet getirecektir [4]. Daha önce de belirtildiği gibi, bakım için zaman limitleri Avrupa Havacılık Güvenliği Ajansı tarafından belirlenir. Bakımlar dört kategori altında, kendi aralarında frekans, içerik ve zaman ile bölünmektedir [5]. A kategori bakımı yaklaşık 65 saatlik uçuş ya da bir haftalık süre ardından yapılsa da, birçok şirket bu bakımları 45 saatlik uçuş sonrasında bir önlem olarak yapmaktadır. Bu bakım içeriği motorlar ve iniş takımları gibi temel parçaların kontrolünü içerir ve genelde bir gecede yapılır. B kategori bakımları 300-600 saatlik uçuşları takiben yapılır ve uçağın genel görsel kontrolü ile hareketli tüm parçaların yağlanmasını içerir. C ve D tipi bakımlar ise 1-4 yılda bir yapılır. Uçağın yapısal bütünlüğünün kontrolü de dahil olmak üzere uçağın tamamen sökülüp tekrardan birleştirilmesini içerir. Bu işlem uçağın yaklaşık bir ay filodan alınması anlamına gelmektedir [1].

$\mathrm{Bu}$ alandaki çalışmalarda, maliyetlerin en aza indirilmesi ve kar maksimizasyonu gibi yaygın amaç fonksiyonlarından kalan uçuş süresinin en aza indirilmesi gibi spesifik örneklere kadar farklı amaç fonksiyonları görülmektedir. Yapılan araştırmalar, erken yapılmış bakımların maliyetleri yıllık bazda önemli bir ölçüde artırdığını göstermiştir [3-67-8]. Bu nedenle, bir uçuş planı belirlenirken, filodaki uçakların kalan uçuş süreleri, bir bakım ihtiyacı için durmadan önce mümkün olan en fazla miktarda kullanılmalıdır. Literatürde bu yaklaşıma göre modelleme yapan ve amaç fonksiyonu oluşturan iki çalışma olduğu görülmüştür. Amaç fonksiyonu, bakımdan önce uçakların kullanılmayan yasal uçuş süresini en aza indirmektir. Bu çalışmalardan ilki, modelde tanımlanan kritik statüyle bir uçağın gelecek uçuş döneminde bakım ihtiyacı olup olmadığına karar vermektedir. Uçağın kalan uçuş süresi, planlanacak periyodun en uzun uçuş ağından daha kısa ise uçak, modele kritik bir uçak olarak katılacaktır. Kritik durumda olmayan uçaklar seti, bakım kısıtlamalarını dikkate almadan haftalık uçuş programını tamamlayacaktır. Öte yandan kritik set, bakım ihtiyaçlarını karşılayabileceği havalimanlarının bulunduğu ağlarda uçurulacaktır [6]. İkinci çalışmada, uçaklar kalan uçuş sürelerine bağlı olmayan bir kuralla düzenlemekte ve bakım verebilecek rotalarda daha az zamanı kalan uçaklara atama 
önceliği tanınmaktadır [8]. Tablo 1'de ilgili çalışmaların s1nıflandırılması görülebilmektedir.

\section{MATERYAL VE YÖNTEM}

Bakım planlamalı uçuş atama modeli geliştirilirken, bir

Tablo 1. Bakım kısıtlı uçak rotalama çalışmaları

\begin{tabular}{|c|c|c|c|c|c|c|}
\hline Yazar & Yll & Veri & \multicolumn{2}{|c|}{ Amaç Fonksiyonu } & Notlar & Programlama \\
\hline Liang vd. [7] & 2015 & Gerçek & \multicolumn{2}{|c|}{ Gecikme min. } & Bakım & IP \\
\hline Basdere ve Bilge [6] & 2013 & Gerçek & \multicolumn{2}{|c|}{ Kalan uçuş süresi min. } & Bakım & IP \\
\hline Diaz-Ramirez vd. [9] & 2013 & Gerçek & \multicolumn{2}{|l|}{ Kar maks. } & Bakım & IP \\
\hline Liang ve Chaovalitwongse [3] & 2013 & Gerçek & \multicolumn{2}{|c|}{ Toplam ceza puanı min. } & Bakım, Filo Atama & Karma IP \\
\hline Orhan vd. [8] & 2011 & Gerçek & \multicolumn{2}{|c|}{ Kalan uçuş süresi min. } & Bakım & IP \\
\hline Lapp ve Cohn [10] & 2011 & Gerçek & \multicolumn{2}{|c|}{ Bakım uyuşmazlığı min. } & Bakım & LP \\
\hline Afsar vd. [11] & 2009 & Gerçek değil & \multicolumn{2}{|c|}{ Fayda maks. } & Bakım & LP \\
\hline El Moudani ve Mora-Camino [12] & 2000 & Gerçek & \multicolumn{2}{|c|}{ Maliyet min. } & Bakım & DP \\
\hline \multicolumn{7}{|c|}{$\begin{array}{l}\text { IP: Tamsayıll Programlama (Integer Programming), LP: Doğrusal Programlama (Linear Programming), DP: Dinamik Programlama (Dynamic Program- } \\
\text { ming) }\end{array}$} \\
\hline \multirow{16}{*}{\multicolumn{3}{|c|}{$\begin{array}{l}\text { önceki bölümde özetlenen literatür incelenmiş ve konu- } \\
\text { nun uygulaması araştırılmıştır. Bu aşamada, uçakların ba- } \\
\text { kım süresinden önce yasal uçuş saatlerini kullanmalarına } \\
\text { ve böylece kullanım verimliliğini artırmalarına ve dolayı- } \\
\text { sıyla bakım maliyetlerini düşürmelerine imkân tanıyan bir } \\
\text { yaklaşım geliştirilmiştir. Aynı zamanda, uçuşlar atanırken } \\
\text { uygun kapasiteli uçuşlara atanması hedeflenmiştir. Bu he- } \\
\text { defler doğrultusunda model iki amaç fonksiyonuna sahip } \\
\text { olacak şekilde geliştirilmiştir. Birinci amaç fonksiyonu, kul- } \\
\text { lanılmayan kalan yasal zamanı minimize etmeye çalışırken, } \\
\text { ikinci amaç fonksiyonu kullanılmamış uçak kapasitesini mi- } \\
\text { nimize etmeye çalışır. Kapasite kullanımını artırmak ve ih- } \\
\text { tiyacı karşılamak için iki yöntem takip edilmiştir. İlk ola- } \\
\text { rak, uçuş taleplerini dikkate alarak, filoda en çok talep gören } \\
\text { uçuşu karşılayabilecek kapasiteye sahip bir uçak seçilmiş- } \\
\text { tir. Bu atama esnasında uçağın, talebi düşük olan herhangi }\end{array}$}} & \multicolumn{4}{|c|}{ Tablo 2. İndisler, parametreler, setler ve karar değişkenleri } \\
\hline & & & $\bar{i}$ & \\
\hline & & & $j$ & \multicolumn{3}{|c|}{ (i) uçuşunu takip edecek uçuş indisi } \\
\hline & & & $k$ & \multicolumn{3}{|c|}{ Uçak indisi } \\
\hline & & & $t_{\mathrm{i}}$ & \multicolumn{3}{|c|}{ Uçuş $(i)$ süresi } \\
\hline & & & $r_{\mathrm{k}}$ & \multicolumn{3}{|c|}{ Uçak $(k)$ kalan uçuş süresi } \\
\hline & & & $c_{\mathrm{k}}$ & \multicolumn{3}{|c|}{ Uçak $(k)$ yolcu kapasitesi } \\
\hline & & & & \multicolumn{3}{|c|}{ Uçuş $(i)$ yolcu talebi } \\
\hline & & & $I$ & \multicolumn{3}{|c|}{ Uçuş seti } \\
\hline & & & $\mathrm{S}(i)$ & \multicolumn{3}{|c|}{ Uçuş $(i)$ 'yi takip edebilecek uçuşlar seti } \\
\hline & & & $\mathrm{P}(i)$ & \multicolumn{3}{|c|}{ Uçuş (i)'ye öncül olabilecek uçuşlar seti } \\
\hline & & & $\mathrm{M}(i)$ & \multicolumn{3}{|c|}{ Uçuş (i)'yi takip eden bakımlar seti } \\
\hline & & & $\{0, T\}$ & \multicolumn{3}{|c|}{ Yapay başlangıç ve bitiş noktaları } \\
\hline & & & $\mathrm{X}_{i j k}$ & \multicolumn{3}{|c|}{$\begin{array}{l}\text { Belirlenen haftada bakım görmeden (k) uçağının sırasıyla (i) ve } \\
\text { (j) uçuşlarını tamamlaması durumunda } 1 \text { değerini alır, diğer du- } \\
\text { rumlarda } 0 \text { değerini alır. }\end{array}$} \\
\hline & & & & \multirow{2}{*}{\multicolumn{3}{|c|}{$\begin{array}{l}\text { Belirlenen haftada bakım gördükten sonra (k) uçağının sırasıyla } \\
\text { (i) ve (j) uçuşlarını tamamlaması durumunda } 1 \text { değerini alır, di- } \\
\text { ğer durumlarda } 0 \text { değerini alır. }\end{array}$}} \\
\hline & & & $\mathrm{Y}_{i j k}$ & & & \\
\hline
\end{tabular}

bir uçuşta boş kalmaması için makul koltuk sayısında olması dikkate alınmıştır. İkincisi, uçuş talebi ile kapasitenin daha etkin kullanılması için, atanacak uçakların kapasitesi ile uçuşa olan talep arasında minimum fark olmasını sağlayacak bir amaç fonksiyonu oluşturulmuştur.

Bu bilgilerin 1şı̆̆ında, bir havayolu şirketinin örnek bir uçuş programı oluşturulmuş ve bu haftalık uçuş programını kapsayan bir filo tespit edilmiştir. Problem, bu veri ve matematiksel modeli kullanarak LINGO programında çözülmüştür. Programlama esnasında kullanılan indisler, parametreler, setler ve karar değişkenleri Tablo 2'de özetlenmiştir.
Amaç fonksiyonu 1:

$\min \sum_{k \in K}\left(1-\sum_{i}^{I} \sum_{j}^{I} \frac{t_{i} x_{i j k}}{r_{k}}\right)$

(Denk. 1)

Amaç fonksiyonu 2:

$\min \sum_{i \in I} \sum_{j \in S(i)} \sum_{k \in K}\left(\frac{\left(x_{i j k}+y_{i j k}\right)\left(c_{k}-d_{i}\right)}{I}\right)$

(Denk. 2)

Kisit 1:

$\sum_{j \in P(i) U\{0\}} x_{j i k}=\sum_{j \in S(i) U\{T\}} x_{i j k}+\sum_{j \in M(i)} y_{i j k} \quad \forall_{i}, \forall_{k} \quad$ (Denk. 3) 
Kisit 2:

$\sum_{k}\left(x_{i j k}+y_{i j k}\right) c_{k} \geq d_{i} \quad \forall_{i}, \forall_{j}$

(Denk. 4)

K1sit 3:

$\sum_{i} \sum_{j \in S(i)} t_{i} x_{i j k} \leq r_{k} \quad \forall_{k}$

(Denk. 5)

Kisit 4:

$\sum_{j \in P(i) \cup\{0\}} y_{j i k}=\sum_{j \in S(i) \cup\{T\}} y_{i j k} \quad \forall_{i}, \forall_{k}$

(Denk. 6)

Kisit 5:

$\sum_{j \in P(i) U\{0\}}\left(x_{j i k}+y_{j i k}\right)=1 \quad \forall_{i}$

(Denk. 7)

Kisit 6:

$\sum_{j \in M(i)} y_{i j k}+\sum_{j \in S(i) U\{T\}}\left(x_{i j k}+y_{i j k}\right)=1 \quad \forall_{i}, \forall_{k}$

(Denk. 8)

Kisit 7:

$x_{i j k}, y_{i j k} \in\{0,1\} \quad \forall_{i}, \forall_{j}, \forall_{k}$

(Denk. 9)

Amaç fonksiyonları ve kısıtların açıklamaları aşağıdaki gibidir:

İlk amaç fonksiyonu (Denk. 1), uçakların planlanan bakımdan önce mümkün olduğunca kullanılmasını amaçlamaktadır. EASA yönetmeliklerine göre uçaklar belirli bir uçuş saatinden sonra bakıma alınmalıdır. Bu amaç fonksiyonu, uçakların uçuş saat limitlerini aşmadan olabildiğince fazla uçuş saatini tamamlamasını sağlamaya çalışmaktadır. Örneğin, bir uçağın 5 saat daha uçuş saati varsa ve hemen bir bakım almasına veya 4 saatlik başka bir rotaya uçmasına olanak sağlayan bir ikilemdeyse, uçakları rotayı uçurmaya zorlar.

İkinci amaç fonksiyonu (Denk. 2), uçakların kapasitelerinin en iyi şekilde kullanılmasını sağlamaya çalışmaktadır. Uçağın kapasitesi gerçekleştirilecek uçuşa olan talebi karşılamalıdır, bu kısıtlarda sağlanmaktadır. Bu amaç fonksiyonu, uçağın verimini en üst düzeye çıkarmak için uçağın, talep düzeyine en yakın kapasitede seçilmesini sağlamaktadır.

Modelde sekiz kısıt vardır. İlk kısıt (Denk. 3), uçuş planını içeren hafta boyunca bakıma girmeyen uçaklar için uçuşları, takip eden uçuşlara ve bakımı dahil eden $\mathrm{X}_{i j k}-\mathrm{Y}_{i j k}$ dönüşümü uçuşlarına bağlar. Bir uçuş bir uçak tarafından gerçekleştirildiğinde, uçak gerçekleştirdiği uçuşu takip edebilecek uçuşların biriyle yoluna devam edebilmektedir. Öncül ve takip eden uçuşlar, kalkış ve iniş havaalanlarından yararlanılarak tasarlanmıştır. Uçağın son iniş yaptığı havalimanından kalkış yapması zorunludur. Uçuş takibi için başka bir kriter de iniş ve kalkış saatleridir. Takip eden uçuşun iniş saatinden 30 dakika sonra kalkması gerekir. Buna ek olarak ilk kısıt bahsedildiği gibi planlanan uçuş programı döneminde bakım alacak uçaklarla ilgili dönüşümleri sağlar. Kısıt, hem tüm uçuşlar hem de uçaklar için oluşturulmuştur. Bir uçak bakıma girdiğinde, uçağın kalan uçuş saatlerini hesaplamamak için model bu uçağın dahil olduğu uçuşların karar değişkenini değiştirmektedir. Ayrıntılı olarak: eğer bir uçağın uçuşu bakım olarak tanımlanan uçuşlardan biri ise, bu uçak bakım sonrasında bakım uçuşunu takip edebilecek uçuşlarından biri ile uçuş programına devam eder.

İkinci kısıt (Denk. 4), seçilen uçağın ilgili uçuşa olan talepten fazla bir kapasiteye sahip olmasını garantilemektedir. Burada 120 ve 150 kapasiteli 2 uçak bulunmaktadır. Uçuş talepleri her uçuş için 100 ila 150 arasında rassal olarak tanımlanmıştır. İkinci amaç fonksiyonu (Denk. 2) uçağın kapasitesi ile uçuşa olan talep arasındaki farkı en aza indirmeye çalışırken, bu kısıt talebin uçağın kapasitesini aşmasını önler. Bu kısıt sayesinde uçuş talebi göz önünde bulundurularak yolcu kapasitesi yetersiz bir uçak atanamamaktadır. Bu kısıt $\mathrm{X}_{i j k}$ ve $\mathrm{Y}_{i j k}$ karar değişkenleri yardımıyla hem bakıma girmiş hem de girmemiş uçakları kapsamaktadır.

İlk amaç fonksiyonu (Denk. 1), uçakların bakımdan önce kullanılmayan izin verilmiş uçuş saatlerini en aza indirmeye çalışmaktadır. Başka bir deyişle, ilk amaç fonksiyonu uçakları mümkün olduğunca kullanmaya çalışır. Bu nedenle model, uçakların kalan uçuş saatlerini aşmamak için bir sınırlamaya ihtiyaç duyar. Burada üçüncü kısıt (Denk. 5) bir sınırlayıcı olarak işlev görür. Uçuşun uçuş süresini $\left(t_{i}\right)$ karar değişkeniyle (Xijk) çarpar ve uçuş programında bu uçak tarafından gerçekleştirilen her uçuşun süresini toplayarak toplam uçuş süresini hesaplar. Burada toplam uçuş saati, uçağın kalan uçuş saatlerini $\left(r_{k}\right)$ aşmamalıdır. Sınırı aşmadan önce, uçak bakım altına alınmalı ve ilk kısıt içerisinde önerilen dönüşüm yapılmalıdır. Bu dönüşüm uçakların, bahse konu uçuş programı sırasında başka bir bakıma ihtiyaç duymayacağı anlamına gelmektedir. Dolayısıyla, üçüncü kısıt $Y_{i j k}$ değişkenini içermez, çünkü model bakımdan sonra uçağın başka bir bakıma daha ihtiyaç duymayacağı bilgisi doğrultusunda bu uçakların uçuş saatlerini hesaplamayı bırakır.

Filodaki uçaklar modele göre bir kere bakım gördükten sonra, tekrar bakıma ihtiyaç duymadan haftalık uçuş programını tamamlayabilmektedir. Herhangi bir uçak bakım gördükten sonra, birinci kısıtın (Denk. 3) yardımıyla karar değişkenini $Y_{i j k}$ 'ye çevirir. Bu dönüşüm modelde uçağın haftalık uçuş programının sonuna kadar tekrar bakım gerektirmeyeceğini garanti altına alır. Karar değişkeni $Y_{i j k}$ 'ye dönüştükten sonra, önceki ve sonraki uçuşlar dördüncü kısıt (Denk. 6) yardımıyla birbirine bağlanır.

Uçuş programı belirlendiğinde, uçuşların birbirini izlediği bir sıra organize edilir. Burada, uçağın kalkış ve iniş havalimanlarının takibi yapılmamaktadır. Bunun yerine, uçuşların kalkış ve iniş saatleri, kalkış ve iniş şehirleri bilgileri 
kullanılarak alt setlerle tanımlanan uçuş bağlantıları kullanılır. Beşinci kısıt (Denk. 7), öncül uçuşların bağlantılarını sağlamaktadır. Bu kısıtla bir uçuşa öncül uçuş olabilecek seçenekler belirlenmekte ve bu seçeneklerden sadece bir tanesinin seçilmesi sağlanmaktadır. Kısıtın ilk bölümünde Xijk karar değişkeni, bakım uçuşlarının öncül uçuşlarını takip etmektedir. Bu bölüm, bakım olarak tanımlanan uçuşlardan önce hangi uçuşların yapılabileceğini belirtir. İkinci bölüm ise normal uçuşlar için aynı şekilde çalışır ve normal uçuşlar öncesinde hangi uçuşların yapılabileceğini belirler. Dolayısıyla, bir uçak, yalnızca önceden tanımlanan uçuşlardan birini yapabilir.

Altıncı kısıt (Denk. 8) ise her hangi bir uçuştan sonra yapılabilecek uçuşları tanımlar. Denklemin ilk kısmı, bakımları takip eden muhtemel uçuşları tanımlarken, ikinci kısmı ise, bakım dışındaki uçuşlarla ilgilidir.

Son kısıt (Denk. 9) ise karar değişkenlerinin 0-1 değerlerini alabileceği ile ilgilidir.

Modelin çözümünde çok amaçlı modellerin çözümü için yaygın olarak kullanılan Öncelikli Hedef Programlama yöntemi kullanılmıştır. Bu metot $\mathrm{n}$ adet amaç fonksiyonu olan bir modelin, amaç fonksiyonlarının önem sırasına göre sıralanması ile başlar. En yüksek öneme sahip amaç fonksiyonu dikkate alınarak, diğer amaç fonksiyonları devre dışı bırakılarak model çözülür. Bulunan amaç fonksiyonu değeri kısıt olarak eklenerek, model ikinci derecede öneme sahip amaç fonksiyonu için çözülür. Bu sayede daha yüksek önem s1rasına sahip olan amaç fonksiyonunun aldığı en iyi değerin korunmasını garanti altına alınır. Süreç bu şekilde tüm amaç fonksiyonları için tekrarlanır [13]. Bu modelde Öncelikli Hedef Programlama metodunun kullanılmasının en önemli sebebi de bu temele dayanır. Uçakların bakıma kadar yasal sınırlar dahilinde uçabilecekleri en fazla saati uçmaları ve uçağın bakımlar arası uçuş süresi veriminin artırılması en önemli amaçtır. Kapasitenin verimli kullanılması ise ikinci öncelikli amaçtır.

\section{BULGULAR VE TARTIŞMA}

Modelin çözümü için gerekli veriler, küçük bir hava yolu şirketinin çevrimiçi yayımlanan uçuş programından alınmıştır. Bu uçuş programı 4 şehirden ve 38 uçuştan oluşan bir ağdır. Uçuş programı yeni şehir ve uçuşlar eklenerek büyütülebilir. Tablo 3 detaylı olarak uçuş programını göstermektedir. Tablo 4 ise filodaki uçakların detaylarını göstermektedir.
Tablo 3. Uçuş programı

\begin{tabular}{|c|c|c|c|c|c|}
\hline \multirow{2}{*}{$\begin{array}{l}\text { Uçuş } \\
\text { No }\end{array}$} & \multirow[t]{2}{*}{ Uçuş } & \multicolumn{3}{|c|}{$\begin{array}{l}\text { Muhtemel takip } \\
\text { eden uçuşlar }\end{array}$} & \multirow[t]{2}{*}{ Muhtemel Bakımlar } \\
\hline & & 1 & 2 & 3 & \\
\hline 1 & İS-İZ 10.20-11.20 & 2 & 8 & 14 & \\
\hline 2 & İZ-İS 12.00-13.00 & 4 & 7 & 9 & \\
\hline 3 & İS-T 12.50-14.10 & 5 & 10 & & \\
\hline 4 & İS-A 14.00-15.20 & 6 & 13 & & \\
\hline 5 & T-İS 14.50-16.10 & 7 & 9 & 11 & \\
\hline 6 & A-İS 16.00-17.20 & 7 & 9 & 11 & \\
\hline 7 & İS-İZ 10.20-11.20 & 8 & 14 & 20 & \\
\hline 8 & İZ-İS 12.00-13.00 & 11 & 12 & 15 & \\
\hline 9 & İS-T 12.50-14.10 & 10 & 17 & & \\
\hline 10 & T-İS 14.50-16.10 & 11 & 12 & 15 & \\
\hline 11 & İS-A 17.30-18.50 & 13 & 18 & & \\
\hline 12 & İS-İZ 19.00-20.00 & 14 & 20 & 24 & \\
\hline 13 & A-İS 19.20-20.40 & 15 & 16 & 19 & \\
\hline 14 & İZ-İS 20.40-21.40 & 15 & 16 & 19 & ${ }^{*} \mathrm{M} 1$ \\
\hline 15 & İS-T 12.50-14.10 & 17 & 28 & & \\
\hline 16 & İS-A 14.00-15.20 & 18 & 22 & & \\
\hline 17 & T-İS 14.50-16.10 & 19 & 21 & 23 & \\
\hline 18 & A-İS 16.00-17.20 & 19 & 21 & 23 & \\
\hline 19 & İS-İZ 19.00-20.00 & 20 & 24 & 26 & \\
\hline 20 & İZ-İS 20.40-21.40 & 21 & 23 & 25 & *M2 \\
\hline 21 & İS-A 17.10-18.30 & 22 & 34 & & \\
\hline 22 & A-İS 19.10-20.30 & 25 & 27 & 29 & \\
\hline 23 & İS-İZ 20.10-21.10 & 24 & 26 & 30 & \\
\hline 24 & İZ-İS 21.50-22.50 & 25 & 27 & 29 & $* \mathrm{M} 3$ \\
\hline 25 & İS-İZ 10.40-11.40 & 26 & 30 & 36 & \\
\hline 26 & İZ-İS 12.10-13.10 & 29 & 31 & 32 & \\
\hline 27 & İS-T 12.50-14.10 & 28 & 33 & & \\
\hline 28 & T-İS 14.50-16.10 & 29 & 31 & 32 & $* \mathrm{M} 4$ \\
\hline 29 & İS-İZ 10.20-11.20 & 30 & 36 & & \\
\hline 30 & İZ-İS 12.00-13.00 & 32 & 35 & 37 & \\
\hline 31 & İS-T 12.50-14.10 & 33 & & & \\
\hline 32 & İS-A 14.00-15.20 & 34 & 38 & & \\
\hline 33 & T-İS 16.00-17.20 & 35 & 37 & & $*$ M5 \\
\hline 34 & A-İS 16.00-17.20 & 35 & 37 & & *M6 \\
\hline 35 & İS-İZ 9.10-10.10 & 36 & $\mathrm{~T}$ & & \\
\hline 36 & İZ-İS 10.40-11.40 & 37 & $\mathrm{~T}$ & & \\
\hline 37 & İS-A 13.00-14.20 & 38 & $\mathrm{~T}$ & & \\
\hline 38 & A-İS 16.00-17.20 & $\mathrm{T}$ & & & \\
\hline
\end{tabular}

Tablo 4. Filo uçakları

\begin{tabular}{llll}
\hline Uçaklar & Kalkış Havalimanı & Kalan uçuş süresi & Uçak kapasitesi \\
\hline $\mathbf{1}$ & İstanbul & 360 saat & 150 \\
$\mathbf{2}$ & İstanbul & 1900 saat & 120 \\
\hline
\end{tabular}

Bu bölümde model Lingo programı ile çözdürüldüğünde yapılan gözlemler özetlenmiştir. 1. amaç fonksiyonu uçakların kalan sürelerini oranlar yardımıyla tespit ederek olabildiğince fazla Xijk değişkenli uçuş yaptırmaya çalışmıştır. Böylece 
uçakların kalan uçuş saatleri mümkün olduğunca kullanılmıştır. 3. kısıt yardımıyla uçakların bu sınırları aşmamaları ve yasal engellere takılmamaları sağlanmıştır. Uçağın bakım görmeden önce uçabileceği uçuş saatleri uçağın kalan uçuş süresini aşamayacağı için 1 . uçak 14. uçuşu tamamladıktan sonra bakıma yönlendirilmiştir. İkinci uçak ise kalan uçuş saatleri yapabileceği uçuşların toplam saatinden daha fazla olduğu için bakım ihtiyacı olmadan uçuş programını tamamlamıştır. Uçuş programı Tablo 5 içerisinde gösterilmiştir.

Tablo 5. Tamamlanmış uçuş programı

\begin{tabular}{|c|c|c|}
\hline & Uçaklar & \\
\hline Uçuşlar & 1 & 2 \\
\hline 1 & & X 1.2.2 \\
\hline 2 & & X 2.4.2 \\
\hline 3 & X 3.5.1 & \\
\hline 4 & & X 4.6.2 \\
\hline 5 & X 5.7.1 & \\
\hline 6 & & \\
\hline 7 & X 7.8.1 & \\
\hline 8 & X 8.12.1 & \\
\hline 9 & & X 9.10.2 \\
\hline 10 & & X 10.11.2 \\
\hline 11 & & X 11.13.2 \\
\hline 12 & X 12.14.1 & \\
\hline 13 & & X 13.15.2 \\
\hline 14 & \begin{tabular}{|l} 
Y 14.16.1 \\
\end{tabular} & \\
\hline 15 & & X 15.17.2 \\
\hline 16 & Y 16.18.1 & \\
\hline 17 & & X 17.19.2 \\
\hline 18 & Y 18.23.1 & \\
\hline 19 & & X 19.20.2 \\
\hline 20 & & X 20.21.2 \\
\hline 21 & & X 21.22.2 \\
\hline 22 & & X 22.25.2 \\
\hline 23 & Y 23.24.1 & \\
\hline 24 & Y 24.27.1 & \\
\hline 25 & & X 25.26.2 \\
\hline 26 & & X 26.31.2 \\
\hline 27 & Y 27.28.1 & \\
\hline 28 & \begin{tabular}{|l|l|} 
Y 28.29 .1 \\
\end{tabular} & \\
\hline 29 & Y 29.30.1 & \\
\hline 30 & \begin{tabular}{|l|l} 
Y 30.32 .1 \\
\end{tabular} & \\
\hline 31 & & \begin{tabular}{|l} 
X 31.33.2 \\
\end{tabular} \\
\hline 32 & Y 2.34.1 & \\
\hline 33 & & X 33.35.2 \\
\hline 34 & Y 34.T.1 & \\
\hline 35 & & X 35.36.2 \\
\hline 36 & & X 36.37.2 \\
\hline 37 & & X 37.38.2 \\
\hline 38 & & X 38.T.2 \\
\hline
\end{tabular}

Veri setinde uçuşların büyük çoğunluğu iki uçağın da karş1layabileceği gibi 120 talepli seçilmiştir. Bu durumda düşük kapasiteli uçağın daha fazla kullanılması beklenmiştir. Burada belirli aralıklarla 150 talepli uçuşlar belirlenerek modelin 2. kısıt desteği ile bu ihtiyacı karşıladığ tir. Yaklaşık yüzde 60 uçuş kapasitesi daha düşük olan ikinci uçak tarafından gerçekleştirilmiştir. Uçuş talepleri genel olarak 120 seviyesinde seyreden uçuşlarda ikinci amaç fonksiyonu sayesinde mümkün olan tüm seçeneklerde kapasite ile talep arasındaki farkı minimumda tutmak adına beklenildiği gibi düşük kapasiteli ikinci uçak atanmıştır.

Çalışma uçuşların bağlanma şekli olarak literatürdeki çalışmaların neredeyse tümünden ayrılmaktadır. Bu anlamda sadece bir çalışma ile aynı metodu kullanmıştır. Bu çalışmada da, Başdere ve Bilge [6] tarafından hazırlanan çalışmada olduğu gibi uçuşlar, zaman ve havalimanı kısıtlarına dahil edilmeyerek, direkt olarak alt setlerle bağlamıştır. Setler de yine zaman ve havalimanı kısıtları göz önüne alınarak belirlenmiştir. Yine literatürde birçok çalışmada maliyetin azaltılması ya da kazancın artırılması sağlanmaya çalışılarak rota belirlenmeye çalış1ırken, bu çalışmada uçakların kalan sürelerinin en üst düzeyde kullanılması amaç fonksiyonu olarak ele alınmıştır. Buna ek olarak literatürde tek olacak şekilde bu amaçla birlikte ikinci amaç olarak uçak kapasiteleri ile atandıkları uçuşun talebi arasındaki farkın minimize edilmesi hedeflenmiştir.

Dinamik fiyatlandırma çalışmalarında uçuşlar için gelişen anlık talep değişimleri sonuçları etkilemektedir. Büyük hacimli olmayan filo-uçuş programı ikilileri için anlık talep değişikliklerinde maksimum kar elde etmek adına atanan uçuşların kapasitelerinin uygun olması sağlanabilir. Tam tersi şekilde, büyük bir uçağın atandığı uçuştaki anlık talep düşüşünün programın tekrar çalıştırılması sayesinde daha küçük bir uçakla karşılanması ve zararın azaltılması adına ikinci amaç fonksiyonu faydalı olacaktır. Şekil.1'de de görüleceği üzere daha az kapasiteye sahip ikinci uçak daha sık kullanılmıştır. Yüksek talep barındıran daha az uçuş olması dolayısıyla, küçük uçağın daha sık kullanılması ikinci amaç fonksiyonunun varlığı sonucunda beklenen bir durumdur.

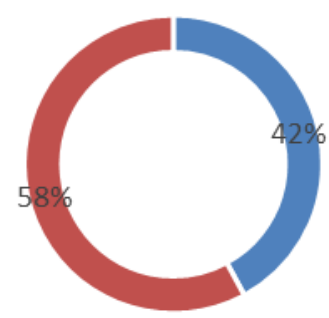

- Uçak 1 - Uçak 2

Şekil 1. Uçakların uçuş tamamlama yüzdeleri 


\section{SONUÇ}

$\mathrm{Bu}$ çalışmada, uçuş setinin atama kararlarının çözümüne ulaşmak adına öncelikle veri setleri gerçek zamanlı uçuşlardan alınarak oluşturulmuş, filo büyüklüğüne karar verilmiştir. Uçakların kapasitesi, kalkış havalimanları ve bakım şehirleri şekillendirilmiştir. Takip eden ve öncül uçuşlar belirlenerek uçuş programının nasıl ilerleyebileceğine, hangi seçeneklerle sonucun farklılaşabileceğine karar verilmiştir. Daha sonra uçuşların nasıl bağlanacağı incelenmiştir. Genel olarak ilgili literatürde şehirlerin ve zamanların bağlanması yolunun izlendiği görülmüştür. Şehir ve zaman kısıtları, kalkışlar, varışlar bu setlerin içerisinde tanımlanarak bağlantı sorunu giderilmiştir. Uçuşlar ilk amaç fonksiyonu sayesinde uçakların kullanılan yasal uçuş saati limitlerinin en yüksek düzeyde kullanılarak bakım almaları için en doğru şekilde sıralanmıştır.

Model göreceli olarak küçük bir veri seti ile çalıştırılmıştır. Uçuş sayısı 38 olan set için 2 uçakla yapılan çalışmada Lingo 9.0 programının $2.8 \mathrm{GHz}$ işlemci hızına sahip bilgisayar ile çözümü bulması 0.8 saniye sürmüştür. Ancak çözümün bulunma hızı gerçek yaşamda, daha büyük boyutlu problemlerde yeterli olmayacaktır. Gelecek çalışmalarda, problemin sezgisel ya da meta-sezgisel metotlarla çözülmesi düşünülebilir.

\section{KAYNAKLAR}

[1] Barnhart, C., Bolant, N., Clarke, L.W., Johnson, E., Nemhauser G., \& Shenoi R.G., (1998). Flight String Models for Aircraft Fleeting and Routing. Transportation Science, 32 (3), 208-220.

[2] Clausen, J., Larsen, A., Larsen, J., \& Rezanova, N.J., (2010). Disruption Management in the Airline Industry-Concepts, models and methods. Computers and Operations Research, 37(5), 809-821.

[3] Liang, Z. \& Chaovalitwongse, W.A., (2013). A Network Based Model for the Integrated Weekly Aircraft Maintenance Routing and Fleet Assignment Problem. Transportation Science, 47(4), 493-507.
[4] Teodorovic, D. \& Stojkovic, G., (1995). Model to Reduce Airline Schedule Disturbances. Journal of Transportation Engineering, July/August, 324-342.

[5] Clarke, L., Johnson, E., Nemhauser, G., \& Zhu, Z., (1997). The Aircraft Rotation Problem. Annals of Operations Research, 69(0), 33-46.

[6] Başdere, M. \& Bilge, Ü., (2013). Operational Aircraft Maintenance Routing Problem with Remaining Time Consideration. European Journal of Operational Research, 235, 315328.

[7] Liang, Z., Feng, Y., Zhang, X., Wu, T., \& Chaovalitwongse, A., (2015). Robust Weekly Aircraft Maintenance Routing Problem and the Extension to the Tail Assignment Problem. Transportation Research Part B, 78, 238-259.

[8] Orhan, I., Kapanoğlu, M., \& Karakoç, T.H., (2011). Concurrent Aircratf Routing and Maintenance Scheduling. Journal of Aeronautics and Space Technologies, 5(1), 73-79.

[9] Diaz-Ramirez, J., Huertas, J.I., \& Trigos, F., (2013). Simultaneous Schedule Design and Routing with Maintenance Constraints for Single Fleet Airlines. International Journal of Engineering and Applied Sciences, 2(2), 23-35.

[10] Lapp, M. \& Cohn, A., (2011). Modifying Lines-of-Flight in the Planning Process for Improved Maintenance Robustness. Computers and Operations Research, 37, 2051-2062.

[11] Afsar, H.M., Espinouse, M.-L., \& Penz, Z., (2009). Building Flight Planning for an Airline Company Under Maintenance Consideration. Journal of Quality in Maintenance Engineering, 15(4), 430-443.

[12] El Moudani, W. \& Mora-Camino, F., (2000). A Dynamic Approach for Aircraft Assignment and Maintenance Scheduling by Airlines. Journal of Air Transport Management, 6, 233237.

[13] Taha, H.A., (2002). Operations Research: An Introduction, 7st Edition. Macmillan Publishing Company, US. 